\title{
Shock Induced Chemical Reactions of Intermetallic Mixture of Nickel and Aluminum and Associated Transition States
}

\author{
Vindhya Narayanan, Sathya Hanagud* \\ Georgia Institute of Technology, Atlanta, GA, USA \\ Email: `hanagud@ae.gatech.edu
}

How to cite this paper: Narayanan, V. and Hanagud, S. (2021) Shock Induced Chemical Reactions of Intermetallic Mixture of Nickel and Aluminum and Associated Transition States. Journal of Materials Science and Chemical Engineering, 9, 60-67.

https://doi.org/10.4236/msce.2021.94007

Received: December 12, 2020

Accepted: April 26, 2021

Published: April 29, 2021

Copyright $\odot 2021$ by author(s) and Scientific Research Publishing Inc. This work is licensed under the Creative Commons Attribution International License (CC BY 4.0).

http://creativecommons.org/licenses/by/4.0/

\begin{abstract}
In this paper, numerical simulation of shock-induced chemical reactions of intermetallic mixtures is discussed. Specifically, the paper focuses on intermetallic mixture of nickel and aluminum. To initiate the chemical reactions, the thermal input or the shockwave should supply the energy to take the reactants, mixture of nickel and aluminum, to the transition state. Thus, for any numerical simulation or analysis of the shock or thermally induced chemical reaction in a continuum scale or a meso scale, it is necessary to identify the transition state. The transition state for the intermetallic mixture of nickel and the aluminum is identified in this paper and a result of the numerical simulation of the shock-induced chemical reaction, in a continuum scale is presented. The numerical solutions clearly show the chemical reactions, release of heat energy, increase of the temperature and the formation of products, following the transition state and the resulting shock-induced chemical reaction of a binary intermetallic energetic mixture of nickel and aluminum. The studies also show that the collapse of porosity is a mechanism that takes the reactants to the transition state, in shock-induced chemical reactions of binary intermetallic mixtures.
\end{abstract}

\section{Keywords}

Transition State, Shock Induced, Chemical Reaction, Void Collapse, NIckel-Aluminum Energetic Mixture

\section{Introduction}

There are two classes of energetic materials [1]. In one class the fuel and the oxidizer are located together in one molecule. Such energetic materials are like 
HMX. The second class of energetic materials is known as reactive materials and has two sub-categories. The first category consists of mixtures of metal and metal oxide. The second sub-category consists of an intermetallic mixture of metals. These intermetallic mixtures offer high mixture density, with the potential to release a significant amount of heat energy, following the chemical reaction. The high density is also associated with high tensile strength and high structural strength. Thus, some of these intermetallic mixtures are ideally suited for dual functional structural-energetic materials. To illustrate, the following table displays a few selected intermetallic mixtures, the associated mixture densities, reaction temperatures and potential release of heat energy [2].

\begin{tabular}{cccc}
\hline Reactive Materials & $\begin{array}{c}\text { Mixture Density } \\
\text { g/cc }\end{array}$ & $\begin{array}{c}\text { Reaction Temperature } \\
\text { Degrees Kelvin }\end{array}$ & $\begin{array}{c}\text { Heat of Reaction } \\
\text { Calories/gram }\end{array}$ \\
\hline $2 \mathrm{~B}+\mathrm{Ti}$ & 3.603 & 3043 & 1320 \\
$\mathrm{Mo}+2 \mathrm{Si}$ & 4.582 & 3498 & 207 \\
$2 \mathrm{~B}+\mathrm{Hf}$ & 8.232 & $3945 / 3653$ & 742 \\
$\mathrm{Al}+\mathrm{Ni}$ & 5.165 & $2362 / 1910$ & 330 \\
$\mathrm{Hf}+\mathrm{C}$ & 9.084 & $4441 / 4222$ & 315 \\
$\mathrm{Al}+\mathrm{Ta}$ & 9.952 & 1011 & 57 \\
\hline
\end{tabular}

To understand the shock-induced chemical reactions theoretically, it is necessary to formulate equations of motion, including the conservation of mass, conservation of energy, nonequilibrium thermodynamics equations, transition states and associated chemical reaction equations. Then, it is also necessary to formulate procedures for numerical simulation of shock-induced chemical reactions and analyze the results. Such a numerical simulation requires procedures to identify the transition states. The objectives of this paper are to illustrate the needed procedures to find transition states in intermetallic mixtures. Because of the availability of the needed literature [3] [4], the intermetallic mixture of nickel and aluminum is selected for finding the transition states and presents a numerical study of the shock-induced chemical reaction.

\section{Transition State}

There are theoretical and experimental studies to understand the reaction mechanisms that explain the shock-induced chemical reactions in intermetallic mixtures. The theoretical studies include supercomputer simulations at the atomistic level. However, most practical applications need a numerical simulation of shock or impact induced simulations of chemical reactions in a continuum or meso scale. For intermetallic mixtures, one option is to use a uniformly blended mixture theory. Then, in a continuum, every point can contain reactants, reaction products and transition states. Then, we formulate conservation equations for mixture variables (mass, momentum and energy equations), mixture constitutive equations and modified reaction equations (modified Arrhenius equa- 
tions), in the framework of equilibrium and non-equilibrium thermodynamics. We know the reactants and products, but we do not know the transition state. Thus, prior to any numerical simulation of shock-induced chemical reactions, it is necessary to determine the transition states.

The next steps of discussions consider the explanations of the term transition state. If we place nickel and aluminum particles on a table at room temperature, in contact with each other, no reactions take place unless we supply some energy to initiate the reaction. This energy that we supply and is sufficient to initiate the reaction is known as the transition state energy. This transition state energy is higher than the energy associated with the reactants, nickel and aluminum, and the product nickel-aluminide. At the transition state, we may have a transition state product that is different from nickel, aluminum or nickel-aluminide.

Studies in transition states are still an active research area [5]. A significant experimental contribution to this field is by Zewail [6]. He used femtosecond spectroscopy to experimentally identify the transition states and their duration in femtoseconds. For example, he studied the ring-opening reaction of cyclobutene into two ethylene molecules and identified a transition state of tetramethylene, with time duration of 700 femtoseconds. In another study he and his colleagues studied the reaction of hydrogen and carbon dioxide into products of $\mathrm{CO}$ and $\mathrm{OH}$. They identified a transition state of HOCO, with time duration of 1000 femtoseconds. Because of these and many other pioneering femtosecond spectroscopy studies, Zewail received the Nobel Prize in 1999.

In this paper, a method is presented to identify transition states for the shock-induced chemical reaction of the intermetallic mixture of nickel and aluminum. The approach is not experimental. The presented procedure is a theoretical method, similar to the method of reference [7].

\subsection{Identification of Transition States for the Shock Induced Chemical Reactions of the Intermetallic Mixture of Nickel and Aluminum}

Of the two components of the mixture, aluminum has a lower melting temperature and hence the chemical reaction initiation criteria are based on the melting temperature of aluminum. The reaction between nickel and aluminum can give

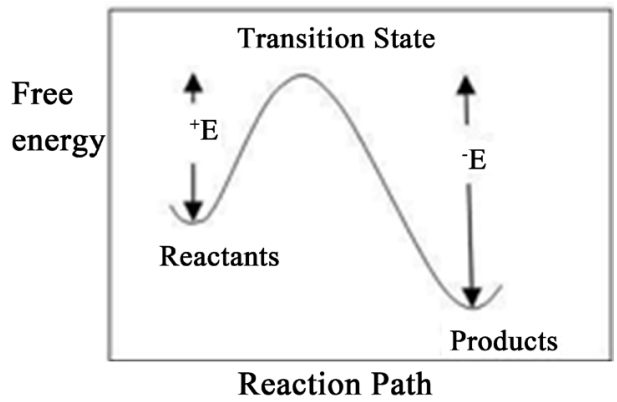

Figure 1. The reaction path from reactants to products. 
rise to different reaction products depending on the starting composition and structure of the mixture [8]. Now, consider two possibilities.

$$
\begin{aligned}
& \mathrm{Ni}+3 \mathrm{Al}=\mathrm{NiAl}_{3} \\
& 3 \mathrm{Ni}+\mathrm{Al}=\mathrm{Ni}_{3} \mathrm{Al}
\end{aligned}
$$

The transition state of both these reactions needs to be identified. The procedure followed is that applied for the thermite mixture [7]. Various compounds that are formed from a stoichiometric composition of nickel and aluminum are identified from the chemical database. The Gibbs free energy of these compounds is then compared. The energy of the transition state must be greater than the energy of both the reactants and products. At the same time, given two possibilities, the one with the lower energy is selected as the transition state. This is because this state would require less supply of energy for the reaction to occur and hence has a high probability of being the transition state of the reaction. Using these guidelines, the possible transition species for Equation (2) were identified as $\mathrm{Ni}(\mathrm{s}) ; \mathrm{Ni}(\mathrm{l}) ; \mathrm{Al}(\mathrm{s}) ; \mathrm{Al}(\mathrm{l}) \mathrm{Ni}, \mathrm{Al}(\mathrm{s}) ; \mathrm{Ni}, \mathrm{Al}(\mathrm{l}) ; \mathrm{Ni}_{3}, \mathrm{Al}(\mathrm{s})$; and $\mathrm{Ni}_{3} \mathrm{Al}(\mathrm{l})$ where " $\mathrm{s}$ " refers to the solid state and "l" the liquid state. The possible reaction path using these transition species are as follows:

a) $\mathrm{Ni}+3 \mathrm{Al}=\mathrm{Ni}(1)+3 \mathrm{Al}(1)=\mathrm{NiAl}_{3}$

b) $\mathrm{Ni}+3 \mathrm{Al}=\mathrm{Ni}(1)+3 \mathrm{Al}(\mathrm{s})=\mathrm{NiAl}_{3}$

c) $\mathrm{Ni}+3 \mathrm{Al}=\mathrm{Ni}(\mathrm{s})+3 \mathrm{Al}(\mathrm{l})=\mathrm{NiAl}_{3}$

d) $\mathrm{Ni}+3 \mathrm{Al}=\mathrm{NiAl}(\mathrm{s})+2 \mathrm{Al}(\mathrm{s})=\mathrm{NiAl}_{3}$

e) $\mathrm{Ni}+3 \mathrm{Al}=\mathrm{NiAl}(\mathrm{s})+2 \mathrm{Al}(\mathrm{l})=\mathrm{NiAl}_{3}$

f) $\mathrm{Ni}+3 \mathrm{Al}=\mathrm{NiAl}(\mathrm{l})+2 \mathrm{Al}(\mathrm{s})=\mathrm{NiAl}_{3}$

g) $\mathrm{Ni}+3 \mathrm{Al}=\mathrm{NiAl}(1)+2 \mathrm{Al}(1)=\mathrm{NiAl}_{3}$

h) $\mathrm{Ni}+3 \mathrm{Al}=0.33 \mathrm{Ni}_{3} \mathrm{Al}(\mathrm{s})+2.67 \mathrm{Al}(\mathrm{l})=\mathrm{NiAl}_{3}$

i) $\mathrm{Ni}+3 \mathrm{Al}=0.33 \mathrm{Ni}_{3} \mathrm{Al}(\mathrm{s})+2.67 \mathrm{Al}(\mathrm{s})=\mathrm{NiAl}_{3}$

j) $\mathrm{Ni}+3 \mathrm{Al}=0.33 \mathrm{Ni}_{3} \mathrm{Al}(1)+2.67 \mathrm{Al}(\mathrm{s})=\mathrm{NiAl}_{3}$

k) $\mathrm{Ni}+3 \mathrm{Al}=0.33 \mathrm{Ni}_{3} \mathrm{Al}(1)+2.67 \mathrm{Al}(1)=\mathrm{NiAl}_{3}$

The Gibbs free energy for each of these transition states is plotted in Figure 2

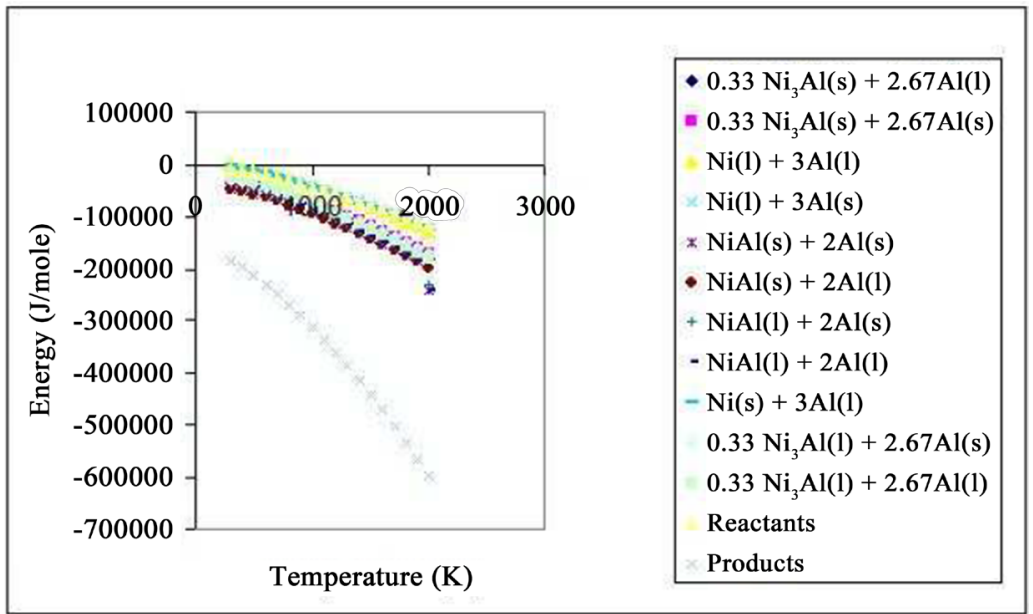

Figure 2. Gibbs free energy and transition states for Equation (1). 
Based on the energy considerations mentioned above, the transition state was identified to be $\mathrm{Ni}(\mathrm{s})+\mathrm{Al}(\mathrm{l})$, as it had energy greater than both the reactants and products and had the lowest energy among all the possible candidate transition states.

Similarly, the transition species for Equation (2) were identified to be $\mathrm{Ni}(\mathrm{s})$, $\mathrm{Ni}(\mathrm{l}), \mathrm{Al}(\mathrm{s}), \mathrm{Al}(\mathrm{l}), \mathrm{NiAl}(\mathrm{s}), \mathrm{NiAl}(\mathrm{l}), \mathrm{NiAl}_{3}(\mathrm{~s})$ and $\mathrm{NiAl}_{3}(\mathrm{l})$. The reaction path for these transition species are as follows:

a) $3 \mathrm{Ni}+\mathrm{Al}=3 \mathrm{Ni}(1)+\mathrm{Al}(1)=\mathrm{Ni}_{3} \mathrm{Al}$

b) $3 \mathrm{Ni}+\mathrm{Al}=3 \mathrm{Ni}(\mathrm{l})+\mathrm{Al}(\mathrm{s})=\mathrm{Ni}_{3} \mathrm{Al}$

c) $3 \mathrm{Ni}+\mathrm{Al}=3 \mathrm{Ni}(\mathrm{s})+\mathrm{Al}(1)=\mathrm{Ni}_{3} \mathrm{Al}$

d) $3 \mathrm{Ni}+\mathrm{Al}=\mathrm{NiAl}(\mathrm{s})+2 \mathrm{Ni}(\mathrm{s})=\mathrm{Ni}_{3} \mathrm{Al}$

e) $3 \mathrm{Ni}+\mathrm{Al}=\mathrm{NiAl}(\mathrm{s})+2 \mathrm{Ni}(1)=\mathrm{Ni}_{3} \mathrm{Al}$

f) $3 \mathrm{Ni}+\mathrm{Al}=\mathrm{NiAl}(\mathrm{l})+2 \mathrm{Ni}(\mathrm{s})=\mathrm{Ni}_{3} \mathrm{Al}$

g) $3 \mathrm{Ni}+\mathrm{Al}=\mathrm{NiAl}(1)+2 \mathrm{Ni}(1)=\mathrm{Ni}_{3} \mathrm{Al}$

h) $3 \mathrm{Ni}+\mathrm{Al}=0.33 \mathrm{NiAl}_{3}(\mathrm{~s})+2.67 \mathrm{Ni}(\mathrm{l})=\mathrm{Ni}_{3} \mathrm{Al}$

i) $3 \mathrm{Ni}+\mathrm{Al}=0.33 \mathrm{NiAl}_{3}(\mathrm{~s})+2.67 \mathrm{Ni}(\mathrm{s})=\mathrm{Ni}_{3} \mathrm{Al}$

j) $3 \mathrm{Ni}+\mathrm{Al}=0.33 \mathrm{NiAl}_{3}(\mathrm{l})+2.67 \mathrm{Ni}(\mathrm{s})=\mathrm{Ni}_{3} \mathrm{Al}$

k) $3 \mathrm{Ni}+\mathrm{Al}=0.33 \mathrm{NiAl}_{3}(1)+2.67 \mathrm{Ni}(1)=\mathrm{Ni}_{3} \mathrm{Al}$

Figure 3 depicts the Gibbs free energy of the transition states along with the reactants and product. Comparison of the energies determines the transition state for the reaction to be $\mathrm{Ni}(\mathrm{l})+\mathrm{Al}(\mathrm{l})$.

\subsection{Shock or Impact Induced Reactions with Identified Transition States}

The transition state and the activation energy for the chemical reaction between the mixture of aluminum and nickel have been identified. The mixture equation of state obtained from the species equation of state has been derived. This equation has also been validated for accuracy. The next step is to analyze the

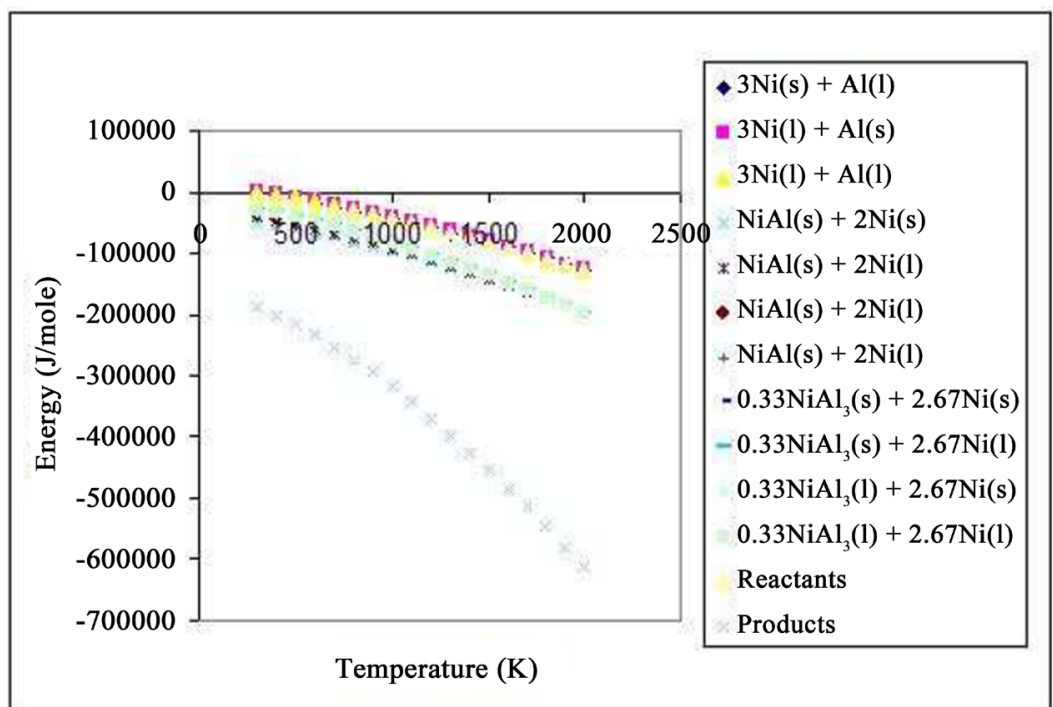

Figure 3. Gibbs free energy and transition states for Equation (2). 
shock-induced chemical reactions in a mixture of $\mathrm{Al}$ and $\mathrm{Ni}$. The problem considered for the numerical simulation is that of the binary energetic material due to different velocities of impact by the impact of a steel projectile. The detailed formulation of equations using mixture theory, in the framework of non-equilibrium thermodynamics, and the associated validation of the second law of thermodynamics will be published separately. Similarly, the modified chemical reaction equations and techniques of numerical implementation are also published separately. For completeness of this paper, selected numerical results, with identified transition states are presented here.

In Figure 4, the variation of the temperature, the formation and the concentration of the product $\mathrm{NiAl}_{3}$ for different impact velocities are illustrated. As the impact velocity increases from $500 \mathrm{~m} / \mathrm{s}$ to $1500 \mathrm{~m} / \mathrm{s}$, the temperature in the system increases. Consequently, the reaction rate increases and the concentration of the product increases. It can also be observed from the figure that once the reaction goes to completion at a particular region, a further increase in temperature does not have any more effect on the reaction process. As the impact velocity increases, more regions of the specimen have a temperature beyond the reaction initiation temperature and hence the reaction process is seen to move spatially into the specimen.

Figure 5 illustrates the effect of the porosity on the reaction process. The void collapse process is one of the mechanisms by which the temperature in the system
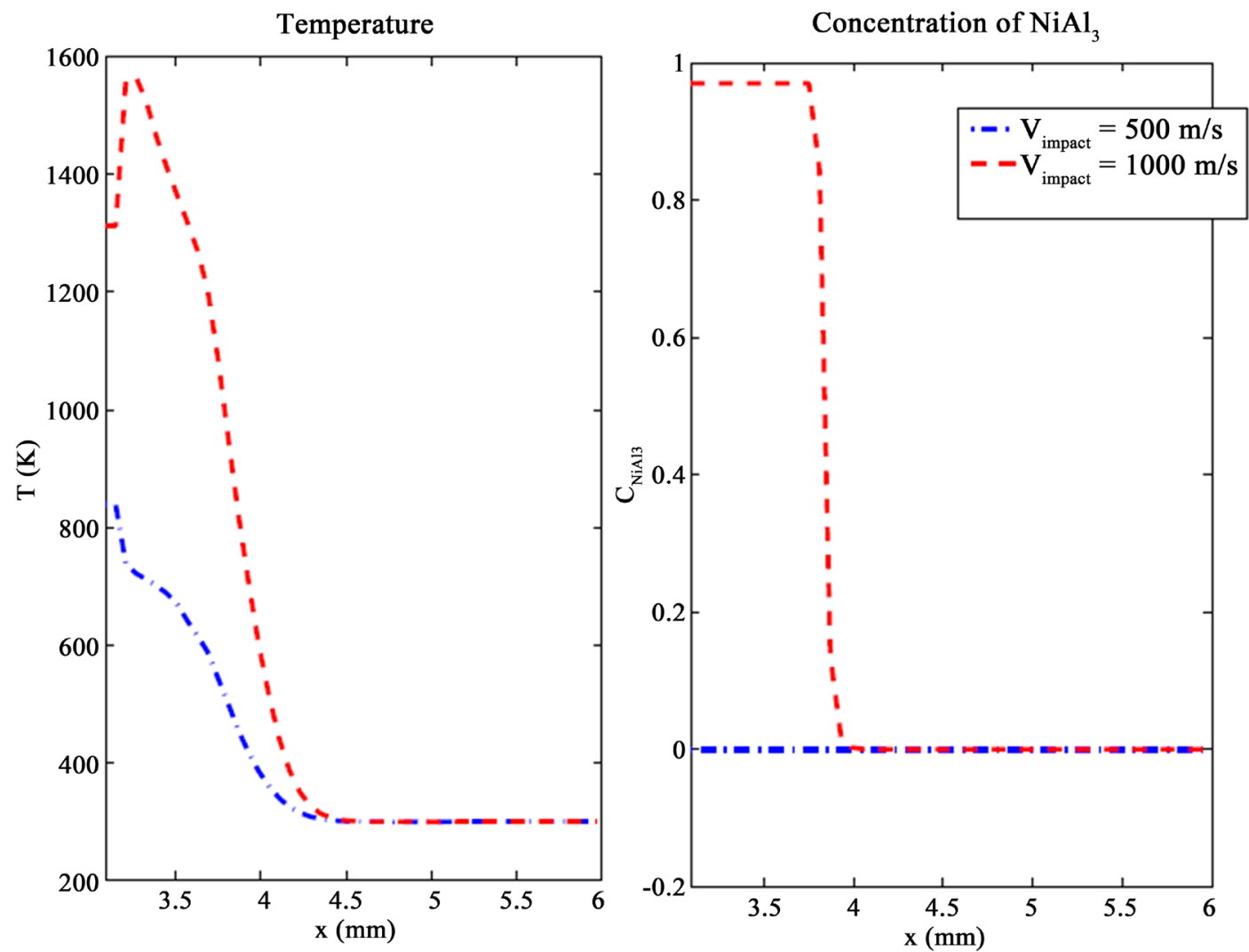

Figure 4. Variations of the temperature and reaction products. 

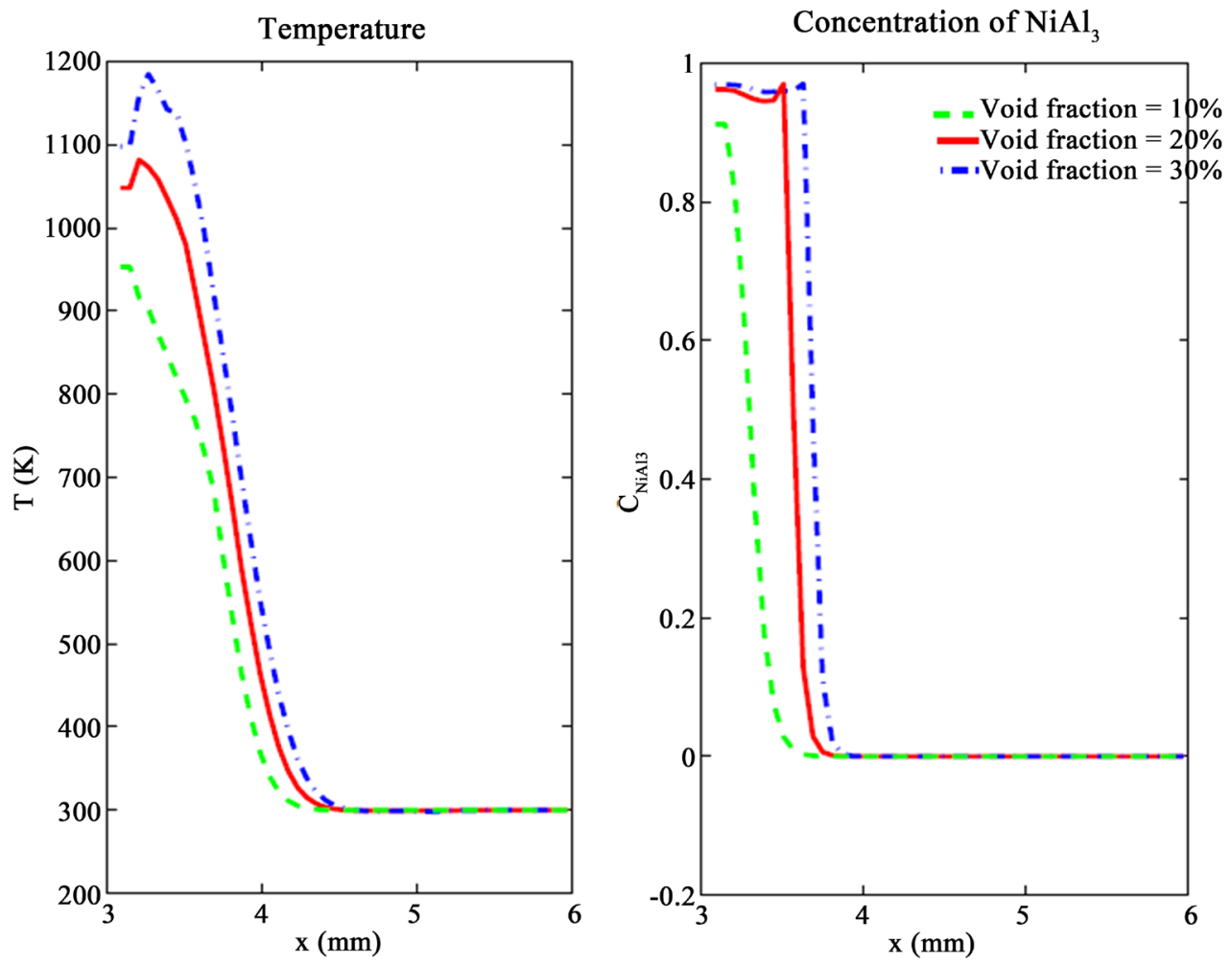

Figure 5. The porosity and the chemical reaction.

is increased to take the reactants to the transition state. As the porosity in the system increases from 0 to $30 \%$, the temperature in the system increases and consequently, the reaction rate increases and thus, the product concentration increases.

\section{Conclusion}

In this paper, we have developed a procedure to determine the transition states for shock or impact-induced chemical reactions of binary energetic materials that are also known as reactive materials. Specifically, the transition states are theoretically obtained for intermetallic mixtures of nickel and aluminum that offer dual functions of structural strength and the capability to release heat energy, following the shock-induced chemical reaction. The derived transition states are then used to study, numerically, the shock-induced chemical reactions, by the use of the mixture theory, conservation equations in the framework of nonequilibrium thermodynamics and modified chemical reaction equations. Effects of varying impact velocities that result in the varying shock velocities are studied. Then, the effect of initial porosity on the shock-induced chemical reactions is studied. The presented numerical studies, on the binary mixture of nickel and aluminum, clearly show the reactions that follow the transition states. The numerical studies also indicate that pore collapse as one of the mechanisms takes the reactants to the transition state, during the shock or impact effect on binary energetic reactants. The methods presented in this paper can be used to study 
shock-induced chemical reactions in the class of intermetallic mixtures of metals.

\section{Conflicts of Interest}

The authors declare no conflicts of interest regarding the publication of this paper.

\section{References}

[1] Narayanan, V. (2005) Non-Equilibrium Thermodynamics of Multifunctional Energetic-Structural Materials. Ph.D. Thesis, Georgia Institute of Technology, Atlanta, GA.

[2] Zaharieva, R. (2015) Abinitio Studies of fhe Equations of State and Chemical Reactions of Reactive Materials. Ph.D. Thesis, Georgia Institute of Technology, Atlanta, GA.

[3] Horie, Y., GrahambI, R.A. and Simonsenc, K. (1985) Synthesis of Nickel Aluminide under High Pressure Shock Loading. Materials Letters, 3, 354-359. https://doi.org/10.1016/0167-577X(85)90075-8

[4] Song, T. and Thadhani, N.N. (1993) Synthesis of Nickel-Aluminum Compounds by Shock Reaction. Journal of Materials Synthesis and Processing, 1, 347-357.

[5] Narayanan,V. and Hanagud, S. (2005) Transition States for Shock Induced Reactions of Binary Energetic Materials. Ph.D. Thesis, Georgia Institute of Technology, Atlanta, GA.

[6] Zewail, A.H. (1999) Femtochemistry: Atomistic-Scale Chemical Dynamics of the Chemical Bond Using Ultrafast Lasers (Nobel Lecture). Angewandte Chemie International Edition, 39, 2586-2631.

[7] Bennet, L.S., Sorrell, F.Y., Simonsen, I.K. and Horie, Y. (1992) Ultrafast Chemical Reactions between Nickel and Aluminum Powders during Shock Loading. Applied Physics Letters, 61, 520-521. https://doi.org/10.1063/1.107874

[8] Duncan, E., Thadhani, N.N. and Graham, R.A. (1993) High Pressure Shock Activation of Nickel and Aluminum Powder Mixtures. Journal of Materials Science, 81, 2903-2914. 